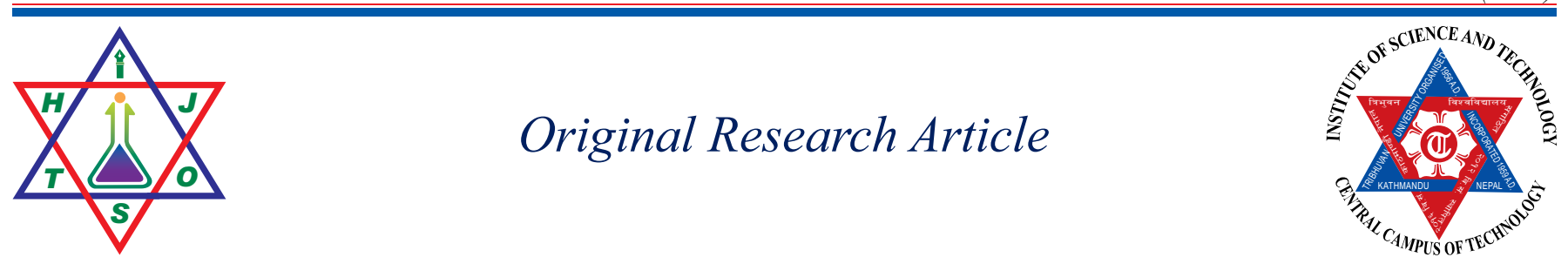

\title{
Risk Factors Associated with Overweight and Obesity among Women of Reproductive Age Residing in Dharan Sub-Metropolitan City, Nepal Prabina Bhattarail ${ }^{*}$, Richa Bhattarai ${ }^{l}$ and Dambar Bahadur Khadka ${ }^{l}$
}

${ }^{1}$ Department of Nutrition and Dietetics, Central Campus of Technology, TU, Dharan, Nepal

*Corresponding author: Prabina Bhattarai, Department of Nutrition and Dietetics, Central Campus of Technology Hattisar, Dharan, Email: bhattaraiprabina28@gmail.com

\begin{abstract}
:
Overweight and obesity is an emerging public health issue in developed world and is also rapidly increasing in developing world. This study was carried out to determine the prevalence and associated risk factors of overweight and obesity among women of child bearing age. A cross sectional study was conducted among 206 women residing in Dharan Sub-Metropolitan city of eastern Nepal. BMI, waist circumference and waist to hip ratio were used as indicators for overweight and obesity based on WHO classification and IDF Classification criteria. Association between socioeconomic factors, dietary factors, physical activity, behavioral factors and health related factors with overweight and obesity among women were assessed by using chi square test. Results showed that $50.48 \%$ women were overweight and obese (BMI > 25), while $89 \%$ based on WHR and, $75.2 \%$ based on waist circumference were abdominally obese. The study also showed that age, marital status, size of family, parity, drinking habit and protein intake were major risk factors for overweight and obesity based on BMI. Abdominal obesity based on waist circumference measurement was associated with age, marital status, parity, TV watching while eating habit, contraceptives use, eating outside and protein intake. The high prevalence of overweight and obesity, and diverse natures of associated risk factors among child bearing age women in Dharan showed that more research in this aspect need to be carried out and concerned agencies should focus on identified risk factors for interventions to reduce existing problems of overweight and obesity among women of reproductive age.
\end{abstract}

Keywords: risk factors, overweight, obesity, reproductive age women, Dharan.

\section{Introduction}

Overweight and obesity is a condition resulting from abnormal or excessive fat accumulation that impairs health of individuals (Chan and Woo, 2010). A person with a BMI of 30 or more is generally considered as obese and a person with a BMI equal to or more than 25 is considered as overweight (CDC, 2017). Waist to hip ratio (WHR) and waist circumference (WC) are the indicators commonly used for central obesity or abdominal obesity (WHO 2008). World Health Organization (WHO, 2009a) has declared overweight as one of the top ten health risks in the world and one of the top five in developed nations. It has been estimated that obesity is the fifth major cause for the death worldwide. Globally, at least 2.8 million adults die each year as a result of being overweight or obese (WHO 2009a). In addition, $44 \%$ of the diabetes burden, $23 \%$ of the ischaemic heart disease burden and between $7 \%$ and $41 \%$ of certain cancer burdens are related to overweight and obesity (WHO, 2009a). There are overwhelming negative effects of overweight and obesity such as insulin resistance, glucose intolerance, diabetes mellitus, hypertension, dyslipidemia, sleep apnea, arthritis, hyperuricemia, gall bladder disease and certain types of cancer (NHLBL, 2013).

Overweight and obesity is a growing global health problem (WHO, 2016). Lack of physical activity combined with unhealthy diet, behavioral factors and other diverse health factors have led to the global epidemic of overweight and obesity (WOF, 2015). Along with these factors, parity level and contraceptive use have also shown to affect overweight and obesity significantly in reproductive aged women (Geyer2013; UN 2012). In 2014, more than 1.9 billion adults, 18 years and older, were overweight out of which more than 600 million were obese (WHO, 2014b). In South East Asia, there is double prevalence of female obesity in comparison to male obesity (Yatsura et al., 2014). International Day for Evaluation of Abdominal Obesity (IDEA) has reported 
highest prevalence of abdominal obesity in South Asian population (Balkau, 2007).

In Nepal trends of overweight and obesity is found to be increasing with $7.1 \%$ overweight and $2.4 \%$ obesity in 2007 to $17.3 \%$ overweight and $4.8 \%$ obesity in 2013 . Similarly, mean waist to hip ratio was found to be 0.55 in 2007 study while 2013 STEPS survey showed the figure was to 0.9 (MOHP 2013; MOHP 2008). The current prevalence of overweight and obesity is more among female as compared to male in Nepal (MOHP, 2013). It

\section{Materials and Methods}

\section{Study Design and settings}

A cross sectional study was conducted to find out the prevalence of overweight and obesity, and the associated risk factors among women residing in Dharan SubMetropolitan city, Nepal. Dharan is located at Sunsari district of Koshi Zone in eastern region of Nepal.

\section{Sample size and sampling technique}

The target population of the study was women of 15 to 49 years of age residing in Dharan sub- metropolitan city. All wards were chosen for sample selection and the number of households from each ward was calculated on the basis of probability proportionate sampling technique. Only one woman from each household was chosen for study. Women who were seriously ill, mentally unfit, pregnant and lactating, residing in hospitals, prisons, nursing homes and those residing temporarily in Dharan were excluded from the study.

The sample size was calculated to represent entire women aged 15-49 years residing in Dharan. In order to achieve this statistical inference, the sample size was determined by using a single proportional formula assuming the combined prevalence rate of overweight and obesity to be $24 \%, 95 \%$ confidence interval (CI), $6 \%$ margin of error (d) and 5\% non-response rate. The WHO STEPS NCD survey conducted in Nepal (MOHP, 2013) was taken as the reference proportion.

\section{Data collection tools and techniques}

The study consisted of anthropometric measurements and dietary survey with the help of semi structured questionnaires. Dependent variables included overweight and obesity (based on BMI), abdominal obesity (based on waist circumference) and waist to hip ratio. Socio-economic and demographic variables, parity, physical activity, dietary factors and health related factors were considered as independent variables.Data was has not only affected the mother's health status, morbidity and mortality but also the healthy births, health of new born babies and later their physical and mental development. Identification of risk factors of overweight and obesity, therefore, could be an essential step for policymakers to develop strategies for its mitigation. Hence, this study was carried out to find out the prevalence of overweight and obesity and its risk factors among women of child bearing age in Dharan SubMetropolitan city, Nepal. collected by using semi structured questionnaire.

Physical activity was categorized as low, moderate and high according to the score calculated by using the short International Physical Activity Questionnaire (IPAQ) (IPAQ, 2002). Adequacy of physical activity for each individual was also determined according to WHO recommendation. Similarly, food frequency questionnaire and the 24- hour recall method were used for dietary assessment by calculating nutrient contents of food with the help of food composition table (DFTQC, 2012) and classifying an adequacy of nutrients according to WHO recommendations (WHO, 2014a).

\section{Anthropometric measurements}

Weight was measured to the nearest of $0.1 \mathrm{~kg}$ by the weighing scale (Micro life) with graduation of $0.1 \mathrm{~kg}$ and measuring capacity up to $180 \mathrm{~kg}$. Weight was taken with light clothing and no shoes. Instrument calibration was performed before weighing each woman. Furthermore, the weighing scale was checked daily against the standard weight for accuracy. Height was measured using the stadiometer with the capacity of $197 \mathrm{~cm}$, standing upright in the middle of the board. The head, shoulders, buttocks, knees and heels touch the vertical board and read near to $0.1 \mathrm{~cm}$. Waist circumference was measured at the mid-point of the lower border of rib cage and the iliac crest using a stretching tape. Hip circumference was measured at a level parallel to floor, at the largest circumference of the buttocks.

BMI was calculated by the formula, BMI $=$ weight $(\mathrm{kg}) /$ height $\left(\mathrm{m}^{2}\right)$. The respondents were divided into three categories (BMI $<25$ as Normal, BMI $25-30$ as overweight and BMI $>30$ as obese) based on BMI cutoffs points of WHO. Similarly based on waist circumference, respondents were divided in two categories (WC $>80 \mathrm{~cm}$ as abdominally obese, and $\mathrm{WC}<80 \mathrm{~cm}$ as normal) and based on waist to hip ratio (WHR $>0.85$ as abdominally obese and WHR $<0.85$ as normal) were made. 


\section{Research ethics}

consistency. Anthropometric data (sex, age, weight, height) were entered into Microsoft excel to calculate

The study was approved by Department of Nutrition and BMI. Likewise, qualitative data were transcribed and Dietetics, Central Campus of Technology and an ethical coded and entered into SPSS version 20.0 by assigning approval was taken from Nepal Health Research Council labels to various categories. Descriptive analysis was used (NHRC). An informed written and verbal consent was obtained from all the participants before data collection.

\section{Data analysis}

to represent percentage and distribution of respondents by socio demographic variables, physical activity, dietary patterns, medical characteristics and behavioral characteristics. . Chi-square test was used to find out

The questionnaires were checked for completeness and factors associated with overweight and obesity in women.

\section{Results and Discussion}

A total of 206 women aged 15-49 years participated in this women was $31 \pm 8.6$ years. Majority of women were study with responsive rate of $100 \%$. The mean age of Janajati (Indigenous caste group). $76.2 \%$ of the women

Table1: Demographic and socioeconomic characteristics of participants $(\mathrm{N}=206)$

\begin{tabular}{|c|c|c|}
\hline Characteristics & Category & Frequency $(\%)$ \\
\hline Religion & Hindu & $188(91.3)$ \\
\hline & Christian & $5(2.4)$ \\
\hline & Buddhist & $12(5.8)$ \\
\hline & Muslim & $1(0.5)$ \\
\hline Caste & Brahmin & $45(21.8)$ \\
\hline & Chhetri & $30(14.6)$ \\
\hline & Janajati & $114(55.3)$ \\
\hline & Dalit & $9(4.4)$ \\
\hline & Madhesi & $7(3.4)$ \\
\hline & Other & $1(0.5)$ \\
\hline Age & $\leq 30$ & $108(52.4)$ \\
\hline & $30-40$ & $64(31.1)$ \\
\hline & $41-49$ & $34(16.5)$ \\
\hline Types of & Nuclear & $183(88.8)$ \\
\hline family & Joint & $23(11.2)$ \\
\hline Family Size & $\leq 5$ & $113(54.9)$ \\
\hline & $>5$ & $93(45.1)$ \\
\hline Marital Status & Married & $157(76.2)$ \\
\hline & Unmarried & $47(22.8)$ \\
\hline & Separated & $2(1.0)$ \\
\hline Parity & Nil & $65(31.55)$ \\
\hline & $1-2$ & $100(48.5)$ \\
\hline & $\geq 3$ & $41(19.9)$ \\
\hline Education & Illiterate & $13(6.3)$ \\
\hline & Primary school & $36(17.5)$ \\
\hline & Middle School & $21(10.2)$ \\
\hline & High School & $63(30.6)$ \\
\hline & Intermediate or higher & $73(35.4)$ \\
\hline Occupation & Employed & $67(32.5)$ \\
\hline & Unemployed & $139(67.5)$ \\
\hline Monthy & $<30,000$ & $95(46.1)$ \\
\hline income & $\geq 30,000$ & $111(53.9)$ \\
\hline
\end{tabular}


were married, $22.8 \%$ were unmarried and $1 \%$ was majority $(53.9 \%)$ of the families had income above Rs separated. Most of the respondents (67.5\%) were 30,000 per months which was more than an average unemployed and majority $(35.4 \%)$ had studied up to income of Nepalese people. Similarly, majority of women intermediated level followed by secondary level (30.6\%), had parity level of $1-2,31.55 \%$ had no parity and primary level $(17.5 \%)$ and illiterate $(6.3 \%)$. Likewise, remaining $19.9 \%$ had parity more than or equal to 3

\section{Prevalence of overweight and obesity}

The survey showed that $32 \%$ (66) were overweight, $16 \%$ (33) were obese and others (107) were normal based on WHO criteria. Based on abdominal obesity, $75.2 \%$ were

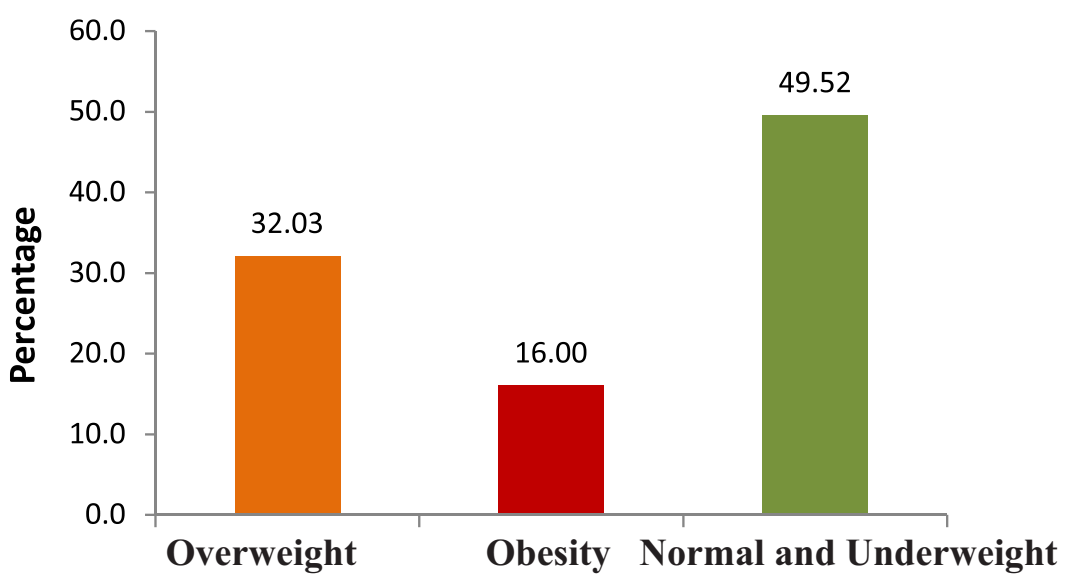

Figure1: Prevalence of overweight and obesity among women of reproductive age residing in Dharan SubMetropolitan city $(\mathrm{N}=206)$

These prevalence of overweight and obesity was found to be comparable to the prevalence of overweight and obesity in male participants of Dharan which was $32.9 \%$ and $7.2 \%$ respectively (Vaidya et al, 2006). Likewise the combined prevalence of overweight and obesity (i.e.58\%) was more than double of the national data on urban female (MOHP, 2011).The abdominal obesity abdominally obese which was calculated by measuring waist circumference, while $89.8 \%(185)$ were abdominally obese according to criteria of WHR.

\section{- Based on Waist Circumference $\quad$ Based on Waist/Hip Ratio}

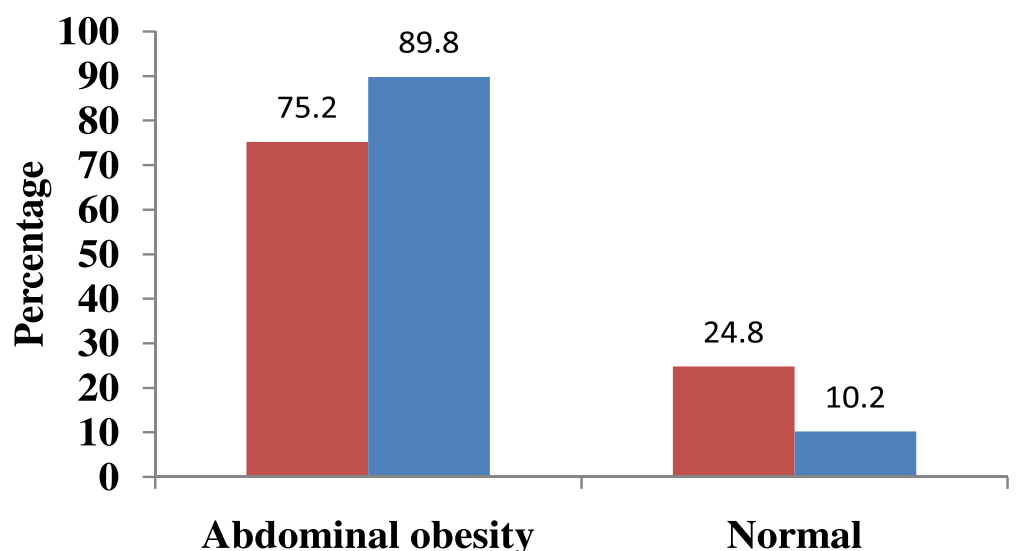

Figure 2: Prevalence of abdominal obesity among women of reproductive age based on Waist circumference criteria (IDF, 2006) and Waist/Hip Ratio (WHO 2016) (N=206) 


\section{Factor associated with overweight and obesity}

The study showed that variables such as; Age $(\mathrm{p}=0.000)$, marital status $(\mathrm{p}=0.004)$, size of family $(\mathrm{p}=0.027)$, parity $(\mathrm{p}=0.019)$, drink $(\mathrm{p}=0.031)$, and protein intake $(\mathrm{p}=0.002)$ were found to be significantly associated with overweight and obesity among the women based on BMI according to WHO cut off level (Table 2). A survey conducted in urban India has also shown that age, marital status and parity could affect the BMI of female of reproductive age (Gauda and Pustry, 2014). Marital status, on the other hand, may affect overweight and obesity because after marriage women become less conscious to their physical appearance (Janghorbani et al., 2008). Similarly, postpartum weight gain in women due to increase in parity (frequency of pregnancy) may cause weight gain and obesity (Martinenz et al., 2013). Similarly, a study conducted in middle school adolescents in Iran supported the findings that family size was directly related to BMI in women (Hajian-Tilaki et al., 2011).

Concerned to abdominal obesity based on waist circumference measurement; Age $(\mathrm{p}=0.000)$, marital status $(\mathrm{p}=0.000)$, parity $(\mathrm{p}=0.0019)$, TV watching habit while eating $(\mathrm{p}=0.049)$, contraceptives use $(\mathrm{p}=0.018)$, eating outside $(p=0.012)$, and protein intake $(p=0.002)$ were found to be significantly associated (Table 3). Based on abdominal overweight and obesity, only parity $(\mathrm{p}=0.017)$ was found to be significantly associated (Table $4)$.

Table-2: Factors associated with overweight and obesity (WHO cut off) among reproductive aged females residing in Dharan Sub-Metropolitan city ( $\mathrm{N}=206)$

\begin{tabular}{|c|c|c|c|c|}
\hline Factors & $\begin{array}{c}\text { Overweight and } \\
\text { obesity } \\
\mathrm{N}(\%)\end{array}$ & $\begin{array}{c}\text { non-overweight and non } \\
\text { obese } \\
\mathrm{N}(\%)\end{array}$ & $\begin{array}{l}\text { Chi-square } \\
\text { value }\end{array}$ & P-value \\
\hline \multirow{3}{*}{ Age (years) } & 41( 37.9$)$ & $67(62.03)$ & 18.556 & $0.001 *$ \\
\hline & $44(68.7)$ & $20(31.25)$ & & \\
\hline & $20(58.8)$ & $14(41.117)$ & & \\
\hline \multicolumn{5}{|l|}{ Size of family } \\
\hline Less than 5 & $48(42.5)$ & $65(57.52)$ & 7.254 & $0.027 *$ \\
\hline Greater than 5 & $57(61.3)$ & $36(38.70)$ & & \\
\hline \multicolumn{5}{|l|}{ Marital status } \\
\hline Unmarried/Separated & $15(30.6)$ & $34(69.38)$ & 15.173 & $0.004 *$ \\
\hline Married & $90(57.3)$ & $67(42.67)$ & & \\
\hline \multicolumn{5}{|l|}{ Alcoholic } \\
\hline Yes & $27(40.9)$ & $39(59.09)$ & 6.947 & $0.031 *$ \\
\hline No & $78(55.7)$ & $62(44.28)$ & & \\
\hline \multicolumn{5}{|l|}{ Protein Intake } \\
\hline Adequate & $25(34.7)$ & $47(65.27)$ & 12.528 & $0.002 *$ \\
\hline Inadequate & $80(59.7)$ & $54(40.29)$ & & \\
\hline \multicolumn{5}{|l|}{ Parity } \\
\hline 0 & $22(33.8)$ & $43(66.153)$ & 18.447 & $0.019 *$ \\
\hline $1-2$ & $57(57.0)$ & $43(43.0)$ & & \\
\hline$\geq 3$ & $25(60.9)$ & $16(39.02)$ & & \\
\hline \multicolumn{5}{|l|}{ Salt intake per day } \\
\hline Greater than 5 gram & $75(52.4)$ & $68(47.55)$ & 4.632 & 0.099 \\
\hline Less than 5 gram & $30(47.6)$ & $33(52.38)$ & & \\
\hline
\end{tabular}

$\mathrm{P}<0.05$ was considered statistically significant

In a study conducted in South Asian population, it was reported that waist circumference increased with age (Amin et al 2015). It is because with age, BMR decreases resulting poor utilization of fat (Fetters, 2015). Likewise some studies supported the fact of gaining abdominal fat in women after marriage. This could be due to change in 
dietary patterns, less focus on being attractive, having more social support and being less physically active (Janghorbani et al., 2008). Likewise, another study showed that high protein intake was associated with low abdominal obesity. This fact is supported by the crosssectional study conducted in multi ethnic population of aboriginal, South Asian, Chinese and Europeans origins (Merchant et al., 2015). Another, study conducted in obese men and women also supported the fact that high protein diet actually helped in losing weight (Farnsworth et al., 2003). High protein diets helps in better utilization of fat and also have high satiety power which prevent people from becoming overweight (Brehm and Dalessio2008). In this study, only parity was found to be significantly associated with abdominal overweight and obesity (based on WHR) in female (Table 3 ). This result was found consistent with the result of the study of reproductive aged women in India (Gauda and Pustry, 2014).

Table 3: Factors associated with abdominal obesity (based on WC) among reproductive aged females residing in Dharan Sub-Metropolitan city ( $\mathrm{N}=206)$

\begin{tabular}{|c|c|c|c|c|}
\hline Factors & Abdominally obese & $\begin{array}{r}\% \text { non-Abdominally } \\
\text { obese }\end{array}$ & $\begin{array}{r}\text { Chi-square } \\
\text { value }\end{array}$ & P-value \\
\hline \multicolumn{5}{|l|}{ Age } \\
\hline Less than 30 & $66(61.1)$ & $42(38.88)$ & 26.642 & $0.000 *$ \\
\hline $30-40$ & $57(89.1)$ & $7(10.93)$ & & \\
\hline $40-49$ & $32(94.1)$ & $2(5.88)$ & & \\
\hline \multicolumn{5}{|l|}{ Marital status } \\
\hline Unmarried/separated & $26(53.01)$ & $23(46.9)$ & 15.614 & $0.000 *$ \\
\hline Married & $129(82.2)$ & $28(17.8)$ & & \\
\hline \multicolumn{5}{|l|}{ Parity } \\
\hline 0 & $37(56.9)$ & $28(43.1)$ & 25.852 & $0.019 *$ \\
\hline $1-2$ & $80(80.0) \mid$ & $20(20.0)$ & & \\
\hline$\geq 3$ & $25(61.0)$ & $16(39.0)$ & & \\
\hline \multicolumn{5}{|l|}{ Tv watching while eating food } \\
\hline Daily & $28(73.7)$ & $10(26.3)$ & 7.879 & $0.049 *$ \\
\hline Twice a week & $19(63.3)$ & $11(36.7)$ & & \\
\hline 3 to 4 times a week & $24(64.9)$ & $13(35.1)$ & & \\
\hline Never & $84(83.2)$ & $17(16.8)$ & & \\
\hline \multicolumn{5}{|l|}{ Eating outside once a day } \\
\hline Once a day & $35(62.5)$ & $21(37.5)$ & 6.704 & $0.012 *$ \\
\hline Never & $120(80.0)$ & $30(20.0)$ & & \\
\hline \multicolumn{5}{|l|}{ Protein intake } \\
\hline Adequate & $45(62.5)$ & $27(37.5)$ & 9.648 & $0.002 *$ \\
\hline Inadequate & $110(82.1)$ & $24(17.9)$ & & \\
\hline \multicolumn{5}{|l|}{ Contraceptive use } \\
\hline Yes & $40(88.9)$ & $5(11.1)$ & 5.756 & $0.018^{*}$ \\
\hline No & $115(71.0)$ & $47(29.0)$ & & \\
\hline
\end{tabular}

$\mathrm{P}<0.05$ was considered statistically significant 
Table-3: Factors associated with abdominal obesity (based onWHR) among reproductive aged females residing in Dharan Sub-Metropolitan city.

\begin{tabular}{|c|c|c|c|c|c|}
\hline & Factors & Abdominal obesity N (\%) & $\begin{array}{l}\text { Non-abdominally } \\
\text { Obesity N (\%) }\end{array}$ & $\begin{array}{l}\text { Chi-square } \\
\text { value }\end{array}$ & P-value \\
\hline \multirow{3}{*}{ Parity } & 0 & $52(80.0)$ & $13(20)$ & \multirow{3}{*}{12.043} & \multirow{3}{*}{$0.017^{*}$} \\
\hline & $1-2$ & $94(94.0)$ & $6(6.0)$ & & \\
\hline & $\geq 3$ & $39(95.1)$ & $2(4.9)$ & & \\
\hline
\end{tabular}

$\mathrm{P}<0.05$ was considered statistically significant

\section{Conclusions}

This study assessed prevalence of overweight and obesity among women of reproductive age residing in Dharan, Nepal. It was found that more than half $(50.48 \%)$ of women were overweight and obese based on BMI. While based on WHR and WC, 89.8\% and $75.2 \%$ were overweight and obese respectively. The main risk factors for overweight and obesity were increasing age, being married, high parity (high Frequency of pregnancy) and low protein intake. The main risk factors for abdominal overweight and obesity (IDF) were increasing age, being married, high parity, low protein intake and also use of contraceptive. There is high prevalence of overweight and obesity in reproductive aged women in Dharan and concerned authorities should emphasize appropriate programs to combat the identified risk factors to control overweight and obesity in the target population.

\section{References}

Amin F, Fatima S, Islam N and Gilani A. Prevalence of obesity and overweight, its clinical markers and associated factors in a high risk South-Asian population. BMC obesity, 2015, 2(16).

Balkau B, Deanfield JE and Despres JP. International day for the evaluation of abdominal obesity (IDEA). Circulation, 2007, 116(17):1942-51.

Brehm B and Dalessio D. Benefits of high protein weight loss diets: enough evidence for practice? Curr Opin Endocrinol Diabetes Obes. 2008, 15(5):416-21.

CDC. Overweight and Obesity. Centre for Disease Control and Prevention. Retrieved from https://www.cdc.gov/obesity/adult/index.html, 2017

Chan RSM and Woo J. Prevention of Overweight and Obesity: How Effective is the Current Public Health Approach. Int. J. Environ Res Public Health. 2010, 7 (3): 765-783.

DFTQC. "Food Composition Table for Nepal".Department of Food Technology and Quality Control, 2012 , Retrieved from http://www.fao.org/fileadmin/templates/food_com position/documents/regional/Nepal_Food_Compo sition_table_2012.pdf.[Accessed 23 January, 2018].

Farnsworth EL, Noakes M, Wittert G, Clifton PM. Effect of a high protein, energy restricted diet on body composition, glycaemic control, and lipid concentrations in overweight and obese hyperinsulinaemic men and women. Am J Clin Nutr, 2003, 78(1):31-9.
Fetters A. How your metabolism changes in your 20s, 30s and 40s. Women's Health. 2015.

Geyer N. Overweight and Obesity in the ReproductiveAge Population of the Central Pennsylvania Women's Health Study. Journal of Obes Weight Loss Therapy,2013, 3:158.

Gouda J and Prusty R. Overweight and Obesity among Women by Economic Stratum in Urban India. $\mathrm{J}$ Health PopulNutr, 2014, 32(1):79-88.

Hajian-Tilaki K, Sajjadi P and Razavi A. Prevalence of overweight and obesity and associated risk factors in urban primary-school children in Babol, Islamic Republic of Iran. East Mediterr Health Journal, 2011, 17 (2), 109

IPAQ. International physical activity questionnaire (August 2002) ; Short last 7 days telephone format ; For use with Young and Middle-aged Adults (15-69 y e a r ) 2002 [ A v a l a ble from : http://uacc.arizona.edu/sites/default/files/ipaq_eng lish telephone_short.pdf.

Janghorbani M, Amini M., Rezvanian, H. Gouya, M. and Delavari, A (2008). Association of body mass index and abdominal obesity with marital status in adults. Arch Iran Med.,11(3):274-81.

Jayatissa R, Hossain S, Gunawardana S, Ranbanda J and Gunathilaka M. Prevalence and associations of overweight among adult womenin Sri Lanka: a national survey. Srilankan journal of diabetes, endocrinology and metabolism. 2012

Martinez M, Pond E, Wertheim B, Nodora J, Jacobs E and Bondy M. Association Between Parity and Obesity in Mexican and Mexican-American Women: 
Findings from the Ella Binational Breast Cancer Study. J Immigr Minor Health, 2013, 2(15):234-43.

Merchant A, Anand S, Vuksan V, Jacobs R, Davis B and Teo K. Protein intake is inversely associated with abdominal obesity in a multi-ethnic population $\mathrm{J}$ Nutr, 2015, 135(5):1196-201.

MOHP. Ministry of Health and Population. Non communicable diseases risk factors. Nepal, 2008

MOHP. Ministry of Health and Population. Non communicable diseases risk factors: STEPS survey Nepal, 2013.

NHLBI, Managing Overweight and Obesity in Adults :Systematic Evidence Review From The Obesity Expert Panel, 2013, [Report]. US

Shapkota A, Sapkota A, Acharya K, Raut M and Jha B. Study of metabolic syndrome in postmenopausal women.Annals of clinical chemistry and laboratory medicine.2015, 1

UN United Nations. Women of reproductive age (15-49 years) 2012 .

Vaidya A, Pokharel P, Nagesh S, Karki P and Majhi S. Association of obesity and physical activity in adult males of Dharan, Nepal. Kathmandu university medical journal, 2006, 4 .
WHO. Waist circumference and $\mathrm{W}$ to $\mathrm{H}$ ratio report of a WHO consultation. World Health Organization 2008.

WHO, Obesity: preventing and managing the global epidemic, World Health Organization technical report series 894, 2004.

WHO. Global Health Risks (Mortality and burden of disease attributable to selected major risks) [Report]. Geneva, 2009.

WHO Organization WH. Obesity global statistics. 2013.

WHO. Guideline: Sodium intake for adult and children [Report]. Geneva, 2014.

WHO. Obesity and Overweight. Retrieved from World Health Organization, 2014. http://www.who.int/ mediacentre/factsheets/fs311/en/.

WHO. Obesity and overweight 2016. Retrieved from http://www.who.int/mediacentre/factsheets/fs311/ en/

Yatsuya H, Li Y, Hilawe E H, Ota A, Wang C, Chiang C, Zhang Y, Uemura M, Osako A, Ozaki Y and Aoyama A. Global trend in overweight and obesity and its association with cardiovascular disease incidence. Circ J, 2014, 78 (12), 2807-18 